\title{
Baseline Interleukin- 6 and -8 predict response and survival in patients with advanced hepatocellular carcinoma treated with sorafenib monotherapy: an exploratory post hoc analysis of the SORAMIC trial
}

\author{
Osman Öcal ${ }^{1}$ (1) $\cdot$ Kerstin Schütte ${ }^{2}$ Juozas Kupčinskas ${ }^{3} \cdot$ Egidijus Morkunas $^{3} \cdot$ Gabija Jurkeviciute $^{3}$. \\ Enrico N. de Toni ${ }^{4} \cdot$ Najib Ben Khaled $^{4}$. Thomas Berg ${ }^{5}$. Peter Malfertheiner ${ }^{4} \cdot$ Heinz Josef Klümpen $^{6}$. \\ Christian Sengel $^{7} \cdot$ Bristi Basu $^{8}$. Juan W. Valle ${ }^{9} \cdot$ Julia Benckert $^{10}$. Antonio Gasbarrini ${ }^{11} \cdot$ Daniel Palmer $^{12}$. \\ Ricarda Seidensticker ${ }^{1} \cdot$ Moritz Wildgruber $^{1} \cdot$ Bruno Sangro $^{13} \cdot$ Maciej Pech $^{14} \cdot$ Jens Ricke $^{1} \cdot$ Max Seidensticker $^{1}$ (I)
}

Received: 20 March 2021 / Accepted: 30 March 2021 / Published online: 14 April 2021

(c) The Author(s) 2021

\begin{abstract}
Purpose To explore the potential correlation between baseline interleukin (IL) values and overall survival or objective response in patients with hepatocellular carcinoma (HCC) receiving sorafenib.

Methods A subset of patients with HCC undergoing sorafenib monotherapy within a prospective multicenter phase II trial (SORAMIC, sorafenib treatment alone vs. combined with Y90 radioembolization) underwent baseline IL-6 and IL-8 assessment before treatment initiation. In this exploratory post hoc analysis, the best cut-off points for baseline IL- 6 and IL- 8 values predicting overall survival (OS) were evaluated, as well as correlation with the objective response.

Results Forty-seven patients (43 male) with a median OS of 13.8 months were analyzed. Cut-off values of 8.58 and 57.9 pg/ $\mathrm{mL}$ most effectively predicted overall survival for IL-6 and IL-8, respectively. Patients with high IL-6 (HR, 4.1 [1.9-8.9], $p<0.001)$ and IL-8 (HR, 2.4 [1.2-4.7], $p=0.009$ ) had significantly shorter overall survival than patients with low IL values. Multivariate analysis confirmed IL-6 (HR, 2.99 [1.22-7.3], $p=0.017$ ) and IL-8 (HR, 2.19 [1.02-4.7], $p=0.044$ ) as independent predictors of OS. Baseline IL-6 and IL- 8 with respective cut-off values predicted objective response rates according to mRECIST in a subset of 42 patients with follow-up imaging available (IL-6, $46.6 \%$ vs. $19.2 \%, p=0.007$; IL-8, $50.0 \%$ vs. $17.4 \%, p=0.011)$.

Conclusion IL-6 and IL-8 baseline values predicted outcomes of sorafenib-treated patients in this well-characterized prospective cohort of the SORAMIC trial. We suggest that the respective cut-off values might serve for validation in larger cohorts, potentially offering guidance for improved patient selection.
\end{abstract}

Keywords Hepatocellular carcinoma $\cdot$ Sorafenib $\cdot$ Interleukin $\cdot$ Response

\section{Introduction}

Hepatocellular carcinoma (HCC) develops mostly on the background of chronic inflammation of the liver (El-Serag 2012). Cytokine signaling, including interleukins (IL), plays an intrinsic role in regulating this inflammatory process, and levels of various cytokines have been shown to be increased in patients with HCC compared to cirrhotic

Max Seidensticker

max.seidensticker@med.uni-muenchen.de

Extended author information available on the last page of the article patients (Kakumu et al. 1993; Naugler et al. 2007; Porta et al. 2008; Bergmann et al. 2017).

Sorafenib, a multitarget tyrosine kinase inhibitor, has been shown to improve survival in patients with advanced HCC (Llovet et al. 2008). However, therapy benefit is not uniform for each patient. Several biomarkers have been investigated to predict the efficacy of sorafenib in HCC patients (Llovet et al. 2012). Additionally, after a long time with sorafenib being the only systemic treatment option for HCC, several first- and second-line therapies emerged (Bruix et al. 2017; Abou-Alfa et al. 2018; Kudo et al. 2018), and recently, atezolizumab-bevacizumab combination has been shown to be superior to sorafenib in the first-line setting (Finn et al. 2020). However, despite these advances, 
sorafenib will undoubtedly continue to be an important treatment option, especially where atezolizumab-bevacizumab is unavailable or contraindicated, and find its new role in the complex HCC treatment algorithm. This situation intensified the need for additional biomarkers of sorafenib benefit. A few preclinical studies have shown that IL-6 and IL- 8 are related to sorafenib resistance (Kahraman et al. 2019; Lai et al. 2019; Li et al. 2020). However, a study that evaluated the prognostic role of multiple biomarkers in HCC patients treated with sorafenib showed that baseline IL- 8 values failed to detect treatment benefit (Miyahara et al. 2011). On the contrary, another study that investigated IL-6 in an Asian HCC cohort showed that pretreatment IL- 6 values with a cut-off of $4.58 \mathrm{pg} / \mathrm{mL}$ are correlated with overall survival after sorafenib, with high pretreatment levels associated with a poor prognosis (Shao et al. 2017).

SORAfenib in combination with local MICro-therapy guided by gadolinium-EOB-DTPA-enhanced MRI (SORAMIC, EudraCT 2009-012576-27, NCT01126645) is a prospective, phase II, randomized, controlled study in HCC patients with three study arms. In the palliative arm of the study, HCC patients were randomized to sorafenib treatment either alone or combined with Y90 radioembolization (RE), and the addition of RE treatment failed to improve survival compared to sorafenib monotherapy (Ricke et al. 2019). This exploratory post hoc analysis of the palliative arm of the SORAMIC trial aimed to explore the predictive value of baseline IL-6 and IL-8 in patients with advanced $\mathrm{HCC}$ receiving sorafenib monotherapy.

\section{Materials and methods}

\section{Study population}

This post hoc analysis was a substudy of the palliative arm of SORAMIC, a prospective, randomized-controlled phase II trial exploring the additional benefit of RE to sorafenib treatment. We selected a subgroup of patients in the palliation arm receiving sorafenib monotherapy only, to eliminate potential effects of other therapies used within the trial (radioembolization). SORAMIC was conducted in 38 centers in Europe and Turkey. The study protocol was approved by the competent authorities as well as the institutional review board, and all patients gave written informed consent.

The inclusion and exclusion criteria for the SORAMIC trial have been described previously (Ricke et al. 2019). In summary, patients aged 18-85 years with a diagnosis HCC in intermediate stage (Barcelona Clinic Liver Cancer [BCLC] stage B, not eligible for TACE) or advanced stage (BCLC C), adequate liver reserve (Child-Pugh scores A to B7), an Eastern Cooperative Oncology Group performance status $($ ECOG PS $) \leq 2$ were eligible. Patients with extrahepatic disease were recruited as long as the disease was liver-dominant

Fig. 1 Consort diagram

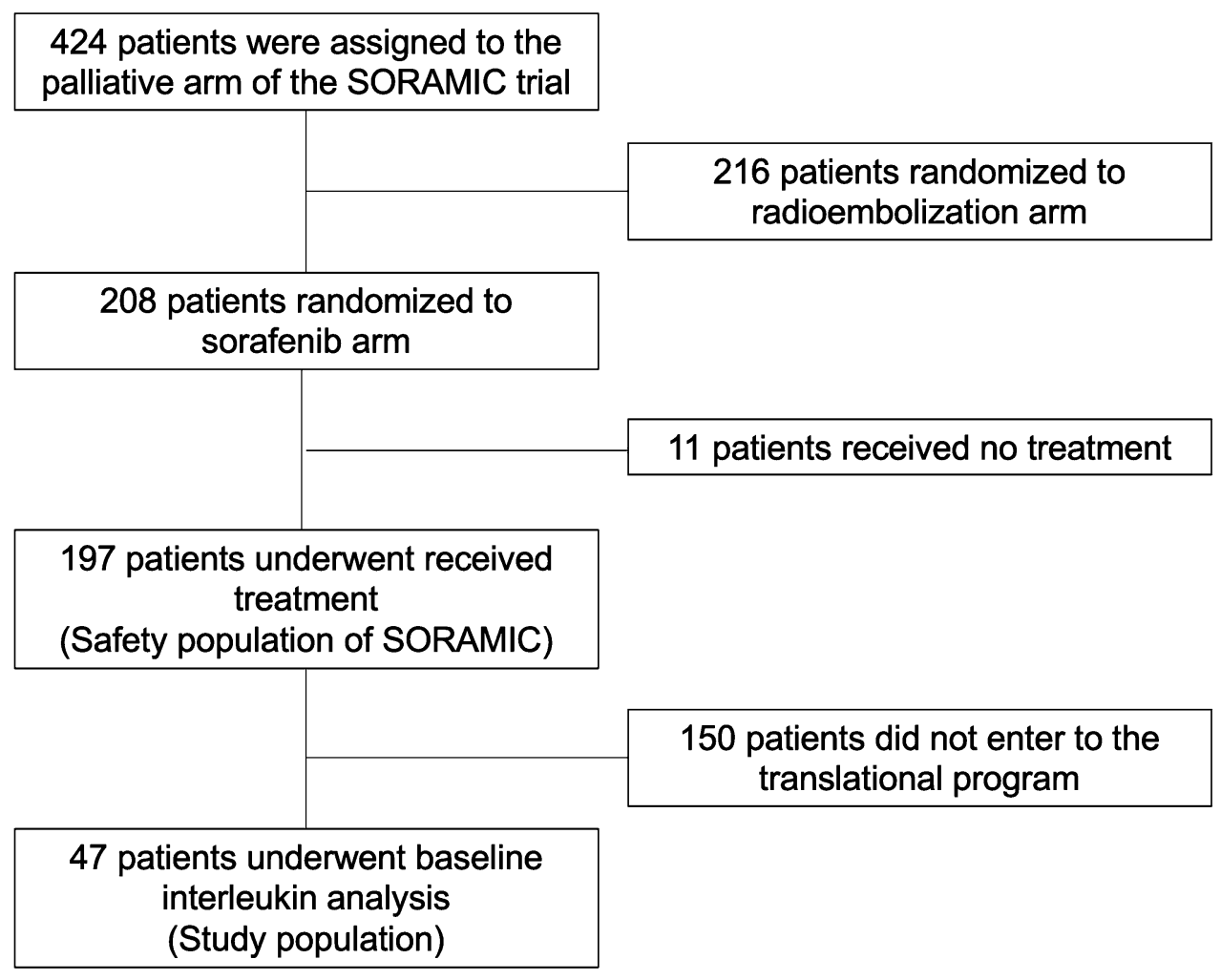


Table 1 Patient characteristics

\begin{tabular}{|c|c|c|}
\hline & Number & $\%$ \\
\hline All cohort & 47 & 100 \\
\hline Gender (male) & 43 & 91.4 \\
\hline Race (White) & 39 & 82.9 \\
\hline Liver cirrhosis (yes) & 41 & 87.2 \\
\hline \multicolumn{3}{|l|}{ HCC etiology } \\
\hline Hepatitis B & 4 & 8.5 \\
\hline Hepatitis C & 9 & 19.1 \\
\hline Hepatitis C & 9 & 19.1 \\
\hline Alcohol & 23 & 48.9 \\
\hline \multicolumn{3}{|l|}{ ECOG PS } \\
\hline 0 & 36 & 76.5 \\
\hline 1 & 11 & 23.4 \\
\hline \multicolumn{3}{|l|}{ Child Pugh score } \\
\hline A & $41(87.2)$ & 87.2 \\
\hline B & $6(12.7)$ & 12.7 \\
\hline \multicolumn{3}{|l|}{ BCLC stage } \\
\hline B & $11(23.4)$ & 23.4 \\
\hline \multirow[t]{2}{*}{$\mathrm{C}$} & $36(76.5)$ & 76.5 \\
\hline & Median & IQR \\
\hline Age (years) & 66 & $60.5-72.5$ \\
\hline Albumin $(\mathrm{g} / \mathrm{dL})$ & 38 & $33-40.7$ \\
\hline Total Bilirubin $(\mu \mathrm{mol} / \mathrm{L})$ & 15.2 & $11-21.2$ \\
\hline $\operatorname{AFP}(n g / m L)$ & 108.7 & $10-1374$ \\
\hline IL-6 (pg/mL) & 9.7 & $4.5-17.5$ \\
\hline IL-8 (pg/mL) & 56.3 & $34.6-172.9$ \\
\hline
\end{tabular}

and lungs were not involved. Inclusion into this substudy required the availability of a blood sample before the initiation of sorafenib treatment to measure IL- 6 and IL- 8 values as part of the translational program of the SORAMIC trial.

Of the 208 patients randomized to sorafenib monotherapy in the palliative arm of the SORAMIC trial and 197 patients received sorafenib within the trial. Of these 197 patients, 47 (23.8\%) were included in the translational program (study population), and baseline blood samples were available for IL assessment (Fig. 1). There was no significant difference in baseline characteristics between the patients who entered the translational program and the rest of the patients who received sorafenib within the trial (Supplementary Table 1). Baseline characteristics of the study population are listed in Table 1. Forty-one (87.2\%) patients had underlying liver cirrhosis. Whereas 23 (48.9\%) patients had alcoholic liver disease (two without cirrhosis), $4(8.5 \%)$ had hepatitis B (one without cirrhosis), and 9 (19.1\%) had hepatitis C. Thirtysix $(76.5 \%)$ patients had advanced HCC (BCLC C), and 41 (87.2\%) had well-preserved (Child-Pugh A) liver function.

Patients were randomized in an 11:10 ratio to receive either combination of RE and sorafenib or sorafenib.
Patients in the sorafenib arm were started sorafenib treatment after randomization with the starting dose of $200 \mathrm{mg}$ twice daily. If tolerated, the dose was escalated to $400 \mathrm{mg}$ twice daily (target dose) after 1 week. Treatment was continued until tumor progression or the emergence of a drugrelated adverse event requiring discontinuation.

Blood samples were obtained before the initiation of the treatment and were stored deep frozen at study core facility and analyzed centrally using Human IL-6 Quantikine ELISA Kit (R\&D Sys, Minneapolis, MN, USA; D6050), and Human IL-8/CXCL8 Quantikine ELISA Kit (R\&D Sys; D8000C), following the manufacturer's instructions. Using enzyme-linked immunosorbent assays, serum levels of the IL6 and IL8 were measured.

As a secondary endpoint, in patients with follow-up imaging available for centralized image analysis, followup images were evaluated according to modified Response Evaluation Criteria in Solid Tumors (mRECIST) by a boardcertified radiologist specialized in gastrointestinal imaging who was blinded to all the clinical information (Llovet and Lencioni 2020). 

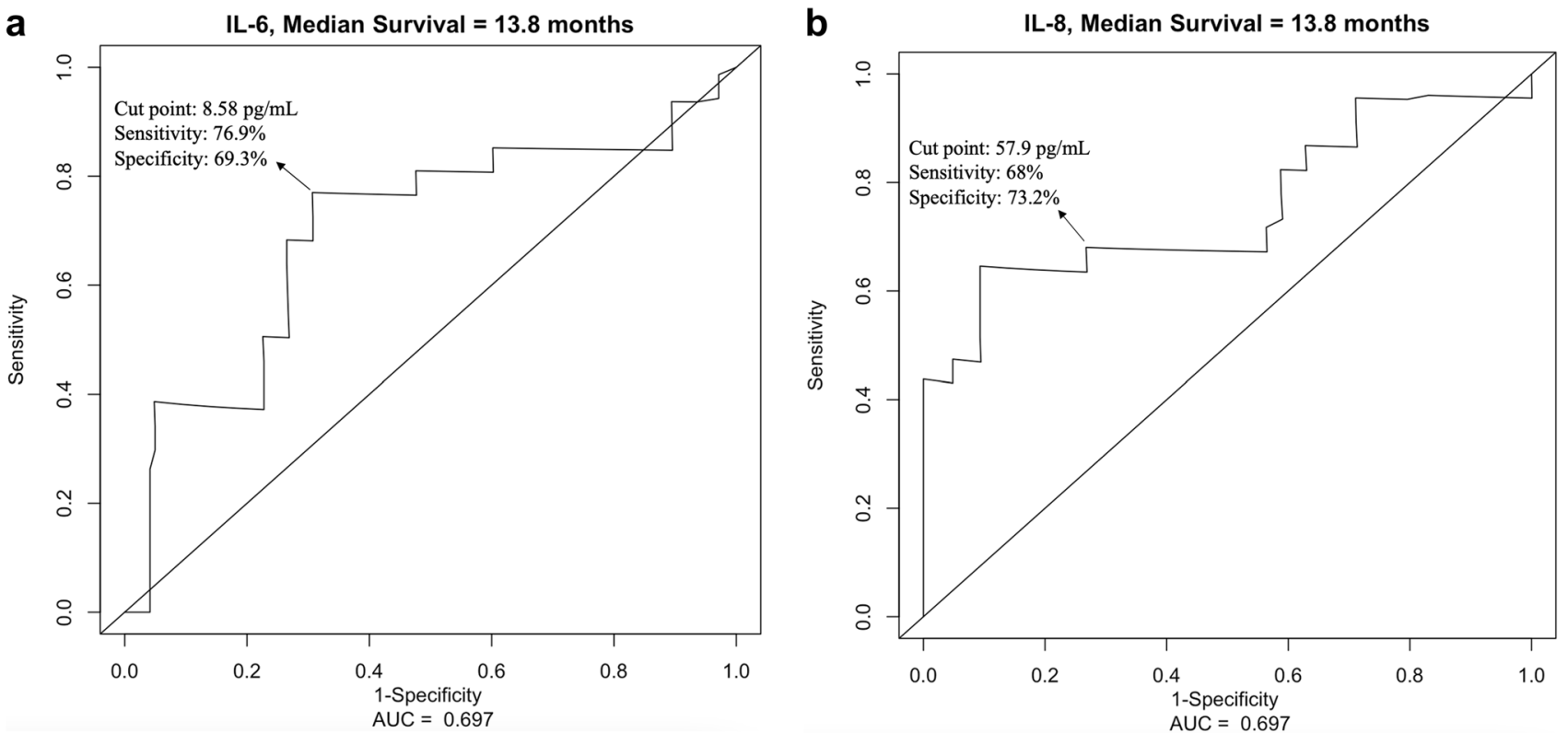

Fig. 2 The receiver-operating characteristics (ROC) curve showing the sensitivity and specificity of various cut-off values of baseline: a interleukin (IL)- 6 and b IL-8 levels to analyze the overall survival

\section{Statistical analysis}

All statistical analyses were performed using R statistical and computing software, version 3.5.0 (http://www.r-proje ct.org). Categorical variables were reported as counts and percentages, and continuous variables as means and standard deviations. Correlations were evaluated with Chi-square and Fisher's exact tests, and a $t$ test was used to compare two groups. We used the receiver-operating characteristic (ROC) curve to determine the cut-off values for IL- 6 and IL- 8 that could produce the highest sensitivity and specificity to predict individual survival shorter than the median overall survival. The Kaplan-Meier method was used for estimates of overall survival, and the log-rank test was used to compare survival groups. Cox regression models were used to assess the effects of cofounding factors on overall survival. Variables with a $p$ value of $<0.1$ in the univariate analyses were analyzed in multivariate Cox regression models to explore prognostic factors of overall survival.

\section{Results}

By the end of the study, 37 (78.7\%) patients had deceased, and the median OS in the subset of patients included in this biomarker analysis was 13.8 months.

Using ROC curve analysis, a cut-off value of $8.58 \mathrm{pg} /$ $\mathrm{mL}$ for IL- 6 was determined to have the highest sensitivity $(76.9 \%)$ and specificity $(69.3 \%)$ to predict survival in these patients (Fig. 2a), whereas an optimal cut-off value of $57.9 \mathrm{pg} / \mathrm{mL}$ was defined for IL-8 for a sensitivity of $68 \%$ and a specificity of $73.2 \%$ (Fig. 2b). Altogether, 26 (55.3\%) patients had IL-6 values higher than $8.58 \mathrm{pg} / \mathrm{mL}$, and 23 (48.9\%) patients had IL-8 values higher than $57.9 \mathrm{pg} / \mathrm{mL}$. Comparison of baseline characteristics of each subgroup according to IL levels is summarized in Table 2.

Univariate analysis of clinical and pathological variables conducted by stratifying patients according to these cutoff values showed that high baseline IL-6 was associated with albumin values of $<36 \mathrm{~g} / \mathrm{L}(p=0.013)$, whereas high baseline IL- 8 was associated with larger maximum tumor diameter $(p=0.013)$. In addition, although the difference was not significant, there were more patients with high IL-6 in patients with larger tumors and ECOG 1; and high IL-8 in patients with total bilirubin $\geq 17 \mu \mathrm{mol} / \mathrm{L}$.

The median overall survival of patients with low IL-6 was 30.3 months (CI 95\% 21.6-NA), while patients with high IL-6 had a median overall survival of 10.3 months (95\% CI 6.7-14.3; $p<0.001 ;$ Fig. 3). Similarly, patients with low IL-8 (30.3 [95\% CI 13.8-NA] months) had significantly longer overall survival than patients with high IL-8 (10.3 [95\% CI 5.5-17.6] months; $p=0.009$; Fig. 4).

Besides IL-6 and IL- 8 values, baseline albumin value $\geq 17 \mathrm{~g} / \mathrm{L} \quad(p=0.008)$ and tumor diameter $\geq 65 \mathrm{~mm}$ $(p=0.021)$ were associated with overall survival, whereas there was a trend for better survival in patients with total bilirubin $<17 \mathrm{~g} / \mathrm{L}(p=0.058)$ and portal vein invasion $(p=0.099)$. There was no correlation between underlying liver disease and overall survival. Multivariate Cox regression analysis revealed that baseline high IL-6 (HR, 2.99 
Table 2 Comparison of baseline characteristics of patients according to IL values

\begin{tabular}{|c|c|c|c|c|c|c|}
\hline & $\begin{array}{l}\text { Overall } \\
(n=47)\end{array}$ & IL 6 high $(n=26)$ & IL 6 low $(n=21)$ & IL 8 high $(n=23)$ & IL 8 low $(n=24)$ & $p$ \\
\hline Gender (male) & 43 (91.4) & $22(84.6)$ & $21(100)$ & $0.11720(86.9)$ & $23(95.8)$ & 0.347 \\
\hline Age ( $\geq 65$ years) & $28(59.5)$ & $16(61.5)$ & $12(57.1)$ & $0.76014(60.8)$ & $14(58.3)$ & 0.859 \\
\hline Race (White) & $39(82.9)$ & $23(88.4)$ & $16(76.1)$ & $0.43719(82.6)$ & $20(83.3)$ & $>0.99$ \\
\hline \multicolumn{7}{|l|}{ ECOG PS } \\
\hline 0 & $36(76.5)$ & $17(65.4)$ & $19(90.5)$ & $0.08017(73.9)$ & $19(79.2)$ & 0.670 \\
\hline 1 & $11(23.4)$ & $9(34.6)$ & $2(9.5)$ & $6(26.1)$ & $5(20.8)$ & \\
\hline Liver cirrhosis (yes) & $41(87.2)$ & $22(84.6)$ & $19(90.5)$ & $0.67819(82.6)$ & $22(91.6)$ & 0.415 \\
\hline \multicolumn{7}{|l|}{ HCC etiology } \\
\hline Hepatitis B & $4(8.5)$ & $3(11.5)$ & $1(4.7)$ & $0.617 \quad 2(8.6)$ & $2(8.3)$ & $>0.99$ \\
\hline Hepatitis C & $9(19.1)$ & $4(15.3)$ & $5(23.8)$ & $0.486 \quad 6(26.0)$ & $3(12.5)$ & 0.286 \\
\hline Alcohol & $23(48.9)$ & $13(50.0)$ & $10(43.4)$ & $0.87111(47.8)$ & $12(50.0)$ & 0.881 \\
\hline Previous TACE & $15(31.9)$ & $7(26.9)$ & $8(38.0)$ & $0.414 \quad 6(26.1)$ & $9(37.5)$ & 0.401 \\
\hline Diffuse disease ( $\geq 10$ lesion $)$ & $32(68)$ & $19(73.0)$ & $13(61.9)$ & $0.41417(73.9)$ & $15(62.5)$ & 0.401 \\
\hline Median (mean) target lesion size, $\mathrm{mm}$ & $53(61.9)$ & $62.5(71.0)$ & $47(50.6)$ & $0.08468(76.5)$ & $49.5(47.9)$ & 0.013 \\
\hline Portal vein infiltration & $28(59.5)$ & $16(61.5)$ & $12(57.1)$ & $0.76016(69.5)$ & $12(50.0)$ & 0.171 \\
\hline Extrahepatic spread & $5(10.6)$ & $3(11.5)$ & $2(9.5)$ & $>0.993(13.0)$ & $2(8.3)$ & 0.666 \\
\hline \multicolumn{7}{|l|}{ Child-Pugh score } \\
\hline A & $41(87.2)$ & $21(80.7)$ & $20(95.2)$ & $0.20418(78.3)$ & $23(95.8)$ & 0.097 \\
\hline $\mathrm{B}$ & $6(12.7)$ & $5(19.2)$ & $1(4.8)$ & $5(21.7)$ & $1(4.2)$ & \\
\hline \multicolumn{7}{|l|}{ BCLC stage } \\
\hline $\mathrm{B}$ & $11(23.4)$ & $4(15.3)$ & $7(33.3)$ & $0.180 \quad 4(17.4)$ & $7(29.2)$ & 0.493 \\
\hline $\mathrm{C}$ & $36(76.5)$ & $22(84.6)$ & $14(66.7)$ & $19(82.6)$ & $17(70.8)$ & \\
\hline Beyond up-to-7 criteria & $42(89.3)$ & $24(92.3)$ & $18(85.7)$ & $0.64421(91.3)$ & $21(87.5)$ & $>0.99$ \\
\hline Total bilirubin $\geq 17 \mu \mathrm{mol} / \mathrm{L}$ & $15(31.9)$ & $11(42.3)$ & $4(19.0)$ & $0.12010(43.4)$ & $5(20.8)$ & 0.095 \\
\hline Albumin $<36 \mathrm{~g} / \mathrm{L}$ & $16(34.0)$ & $13(50.0)$ & $3(14.2)$ & $\mathbf{0 . 0 1 3} 10(43.4)$ & $6(25.0)$ & 0.181 \\
\hline $\mathrm{AFP} \geq 400 \mathrm{ng} / \mathrm{mL}$ & $17(36.1)$ & $10(38.4)$ & $7(33.3)$ & $0.7319(39.1)$ & $8(33.3)$ & 0.848 \\
\hline Objective response & $16(38.0)$ & $5(19.2)$ & $11(46.6)$ & $\mathbf{0 . 0 0 7} 4(17.4)$ & $12(50.0)$ & 0.011 \\
\hline
\end{tabular}

Bold type indicates statistical significance

[95\% CI 1.22-7.3]; $p=0.017)$ and high IL-8 (HR, 2.19 [95\% CI 1.02-4.7]; $p=0.044$ ) values were the only independent predictors of shorter overall survival (Table 3 ).

The estimated rates of survival at 6 months and 12 months were $95.2 \%$ and $66.6 \%$, respectively, in patients with IL- $6<8.58 \mathrm{pg} / \mathrm{mL}$ and $100 \%$ and $66.6 \%$ in patients with IL- $8<57.9 \mathrm{pg} / \mathrm{mL}$.

Patients were scored according to IL levels as follows: both IL-6 and IL-8 lower than cut-off values (score 0), one of IL- 6 or IL- 8 higher than the cut-off (score 1), and both higher than the cut-off (score 2). Fifteen patients had score 0 , 15 had score 1 , and 17 had score 2 . While the median OS of patients with score 0 was 37.7 (CI 95\% 14.8-NA) months, score 1 was 16.3 (CI 95\% 9.8-NA) months, and score 2 was 9.5 (CI 95\% 5.1-14.3) months (Fig. 5).

For 42 (89.3\%) patients, follow-up images were available. Response assessment according to mRECIST revealed an objective response in 16 (38.0\%) patients. Patients with IL-6 values lower than cut-off had a significantly higher objective response rate than patients with IL- $6 \geq 8.58 \mathrm{pg} / \mathrm{mL}(46.6 \%$ vs. $19.2 \%, p=0.007)$. Similarly, low IL- 8 values were also significantly associated with a higher objective response rate (50.0\% vs. $17.4 \%, p=0.011)$.

\section{Discussion}

In the presented exploratory study, we define baseline levels of IL-6 and IL-8 as prognostic biomarkers of overall survival in patients with advanced HCC undergoing sorafenib treatment by identifying cut-off values of $8.58 \mathrm{pg} / \mathrm{mL}$ and $57.9 \mathrm{pg} / \mathrm{mL}$ for IL-6 and IL-8, respectively. Baseline IL-6 and IL-8 levels with respective cut-off values remained the only independent predictors of overall survival after adjusting for multiple prognostic factors in the multivariate analysis. In addition, these cut-off values were also associated with objective response in follow-up imaging. 
Fig. 3 Kaplan-Meier curve showing overall survival of patients grouped by baseline IL-6 values according to cut-off of $8.58 \mathrm{pg} / \mathrm{mL}$
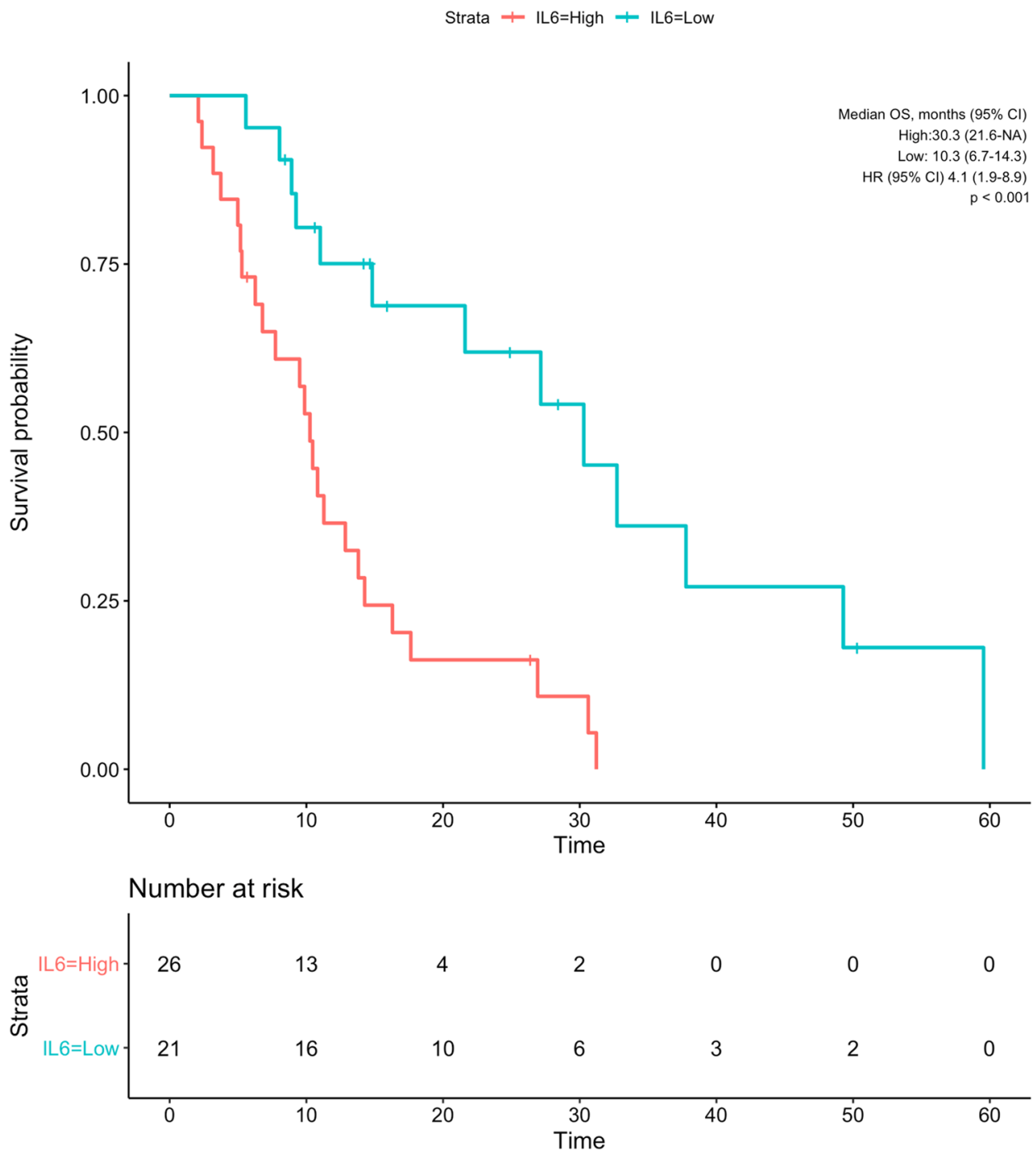

Previous studies have shown that higher IL-6 and IL-8 levels are associated with increased HCC risk in patients with chronic liver disease (Wong et al. 2009; Chien et al. 2011) and correlated with advanced disease stages (Sanmamed et al. 2014; Wang et al. 2016; Sun et al. 2019) and worse liver function in patients with HCC (Chan et al. 2012; Jang et al. 2012). High baseline IL-6 and IL-8 values have been also shown to correlate with treatment response and overall survival in patients who received minimally invasive locoregional therapies (Jang et al. 2012; Carpizo et al. 2014; Seidensticker et al. 2017). A study that investigated the prognostic role of baseline IL-8 under sorafenib treatment in a Japanese HCC cohort, in which $86.7 \%$ of the patients had viral hepatitis, showed no correlation between baseline IL-8 levels and treatment response or survival (Miyahara et al. 2011). A single study in the literature explored IL-6 as a predictor in HCC patients receiving sorafenib (55 and 73 patients in exploration and validation cohorts) showed a cut-off value of $4.28 \mathrm{pg} / \mathrm{mL}$ could predict survival (HR, 2.5 [1.3-5.0], $p=0.005$ ) in an Asian cohort (Shao et al. 2017). Most patients $(98.1 \%)$ in this study had viral hepatitis. The application of this cut-off value to our cohort failed to detect a survival benefit (data not shown). ROC analysis of the SORAMIC cohort revealed the cut-off value of $8.58 \mathrm{pg} / \mathrm{mL}$ for IL-6 with a sensitivity of $76.9 \%$ and specificity of $69.3 \%$ to predict individual survival longer than the median survival of the cohort. This discrepancy may represent the differences between Asian and Western cohorts and the need for different cut-off values for each. For example, while the most common underlying etiology was the alcoholic liver disease with $48.9 \%$ of the patients, and the rate of viral hepatitis was $27.6 \%$ in our cohort; the vast majority of patients (86.7-98\%) in previously 
Fig. 4 Kaplan-Meier curve showing overall survival of patients grouped by baseline IL-8 values according to cut-off of $59.7 \mathrm{pg} / \mathrm{mL}$
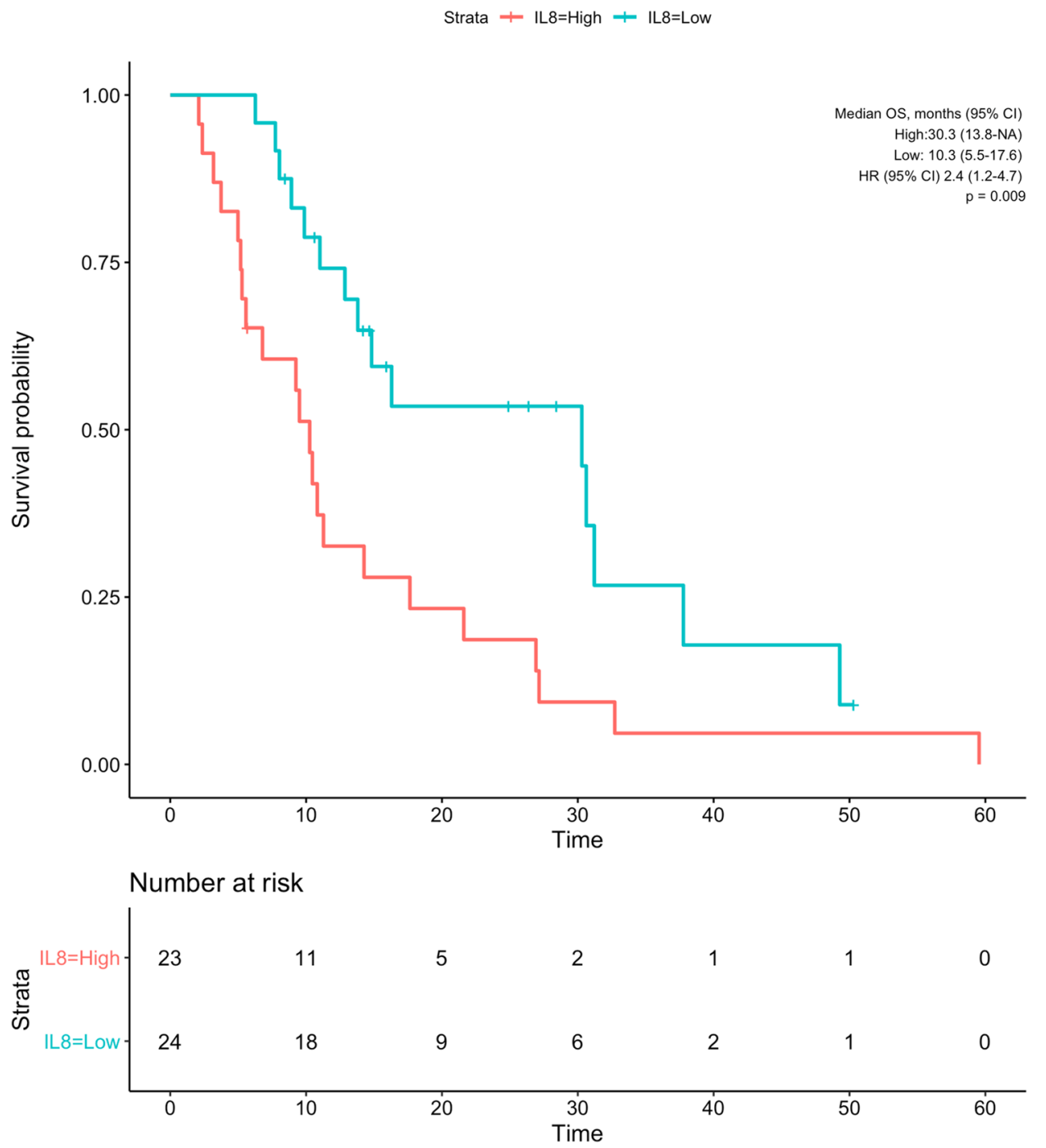

mentioned Asian cohorts had viral hepatitis (Miyahara et al. 2011; Shao et al. 2017). However, testing for the influence of etiology of underlying disease in our analysis did not identify a significant difference in IL values. This might be the result of small numbers and a combination of different causative factors. The cut-off value described in our study is in the range of previously reported cut-off values for IL- 6 to detect survival benefit of HCC patients who underwent transarterial chemoembolization $(10 \mathrm{pg} /$ $\mathrm{mL}$ ) and radioembolization $(6.53 \mathrm{pg} / \mathrm{mL})$ (Jang et al. 2012; Seidensticker et al. 2017). Furthermore, the identified cut-off values for IL- 6 and IL- 8 were also correlated with objective response during follow-up (according to mRECIST), demonstrating the capacity of baseline IL-6 and IL-8 as potential prognostic biomarkers.

IL-6 is a pro-inflammatory cytokine and induces the production of acute-phase reactants in the liver. It is also associated with cell proliferation, resistance to apoptosis and chemotherapeutics, and metastasis (Naugler et al. 2007; Schmidt-Arras and Rose-John 2016). IL-8 is a macrophage-derived cytokine that induces tumor angiogenesis and recruitment of immunosuppressive cells to the tumor (Koch et al. 1992; Fousek et al. 2020). Preclinical studies have shown that IL-6/STAT3 signaling contributes to sorafenib resistance in HCC cell lines, and blockage of IL-6 increases cytotoxicity of sorafenib (Niu et al. 2018; Lai et al. 2019; Li et al. 2020). Similarly, inhibition of IL-8 signaling reduces stem cell population in HCC and increases sorafenib sensitivity of tumor cells (Kahraman et al. 2019). Although both IL-6 and IL- 8 are related to sorafenib resistance, mechanisms of action are through different pathways. The difference in the mechanisms of IL-6 and IL-8 was partially represented by our cohort. Whereas IL-6 was associated with albumin values and 
Table 3 Univariate and multivariate analyses of factors associated with overall survival

\begin{tabular}{|c|c|c|c|c|}
\hline \multirow[t]{2}{*}{ Parameter } & \multicolumn{2}{|l|}{ Univariate analysis } & \multicolumn{2}{|c|}{ Multivariate analysis } \\
\hline & HR $(95 \% \mathrm{CI})$ & $p$ value & HR $(95 \% \mathrm{CI})$ & $p$ value \\
\hline High IL-6 & $4.1(1.9-8.9)$ & $<0.001$ & $2.99(1.22-7.3)$ & 0.017 \\
\hline High IL-8 & $2.4(1.2-4.7)$ & 0.009 & $2.19(1.02-4.7)$ & 0.044 \\
\hline Sex (male vs. female) & $0.79(0.28-2.3)$ & 0.667 & & \\
\hline Age ( $\geq 65$ vs. $<65$ years $)$ & $1.1(0.55-2.1)$ & 0.85 & & \\
\hline ECOG PS (1 vs. 0) & $0.63(0.28-1.4)$ & 0.263 & & \\
\hline Cirrhosis (yes vs. no) & $0.63(0.24-1.7)$ & 0.35 & & \\
\hline Hepatitis B etiology (yes vs. no) & $1.1(0.34-3.7)$ & 0.865 & & \\
\hline Hepatitis C etiology (yes vs. no) & $1.5(0.68-3.1)$ & 0.335 & & \\
\hline Alcohol etiology (yes vs. no) & $0.61(0.3-1.2)$ & 0.164 & & \\
\hline TACE history (Yes vs. No) & $1.2(0.61-2.5)$ & 0.578 & & \\
\hline PVI (yes vs. no) & $0.55(0.27-1.1)$ & 0.099 & $0.66(0.29-1.53)$ & 0.337 \\
\hline Child-Pugh score (B vs. A) & $1.5(0.59-4.1)$ & 0.377 & & \\
\hline BCLC stage (C vs. B) & $0.57(0.26-1.2)$ & 0.155 & & \\
\hline Beyond up-to-7 (yes vs. no) & $1.5(0.44-4.8)$ & 0.536 & & \\
\hline Tumor diameter $(\geq 65$ vs. $<65 \mathrm{~mm})$ & $2.2(1.1-4.4)$ & 0.021 & $1.31(0.54-3.18)$ & 0.545 \\
\hline $\operatorname{AFP}(\geq 400 \mathrm{vs}<400 \mathrm{ng} / \mathrm{mL})$ & $1.1(0.54-2.4)$ & 0.745 & & \\
\hline Diffuse disease ( $\geq 10$ lesions) & $1.3(0.64-2.7)$ & 0.457 & & \\
\hline Extrahepatic disease & $1.6(0.48-5.5)$ & 0.431 & & \\
\hline Albumin & $0.37(0.17-0.77)$ & 0.008 & $0.72(0.29-1.8)$ & 0.483 \\
\hline Bilirubin & $0.51(0.25-1)$ & 0.058 & $0.83(0.38-1.84)$ & 0.649 \\
\hline
\end{tabular}

Bold type indicates statistical significance had a tendency to be higher in patients with worse performance status and larger tumors, IL-8 was associated with tumor diameter and partly correlated with bilirubin values. These findings are consistent with the previous studies (Jang et al. 2012; Sanmamed et al. 2014). In addition to these, when patients were scored according to IL levels ( 2 being both high, 1 either IL- 6 or IL- 8 high, and 0 both low), those with higher scores had significantly shorter overall survival. This highlights the importance of recognizing both baseline IL- 6 and IL-8 values as interacting prognostic factors to cover both of liver inflammation/injury and tumor-related factors.

Recently, Imbrave 150 trial has shown that the combination of atezolizumab with bevacizumab improved both overall and progression-free survival as compared to sorafenib (Finn et al. 2020). Despite the promising results of this and similar studies, not all patients are ideal candidates for atezolizumab and bevacizumab therapy. For example, patients with autoimmune diseases or organ transplant recipients were excluded from the Imbrave 150 trial, as well as patients with Child-Pugh class B liver function. The high cost, iv. application need, and toxicity of the immunotherapies might prevent rapid worldwide implementation of these therapies. Additionally, atezolizumab-bevacizumab has shown to be not cost-effective as compared to sorafenib
(Wang et al. 2021), which will restrict its use, especially in resource-limited countries. Furthermore, sorafenib will remain an important second-line treatment option in patients who progressed after atezolizumab-bevacizumab (Kudo 2021), and optimized treatment decision-making needs to be supported. For example, the survival rate at 12 months of atezolizumab-bevacizumab-treated patients was $67.2 \%$ in the IMbrave150 study (Finn et al. 2020), and patients with IL-6 or IL-8 values lower than cut-off values had similar rates of overall survival (66.6\%) at the same time point in our study under sorafenib. For better utilization of limited resources, baseline IL values can potentially serve in risk stratification and patient allocation into therapies once validated. Therefore, further evaluation of the additional benefit of therapies suppressing IL pathways to current therapies in HCC patients with high baseline IL values is warranted. Besides this, baseline measurements of IL- 6 and IL- 8 should be used to stratify patients between treatment arms in future phase 3 trials for new drugs to improve patient selection for the therapy and avoid confounders.

This study has some limitations. Blood sampling for the translational program was not mandatory in the SORAMIC trial, and 18 of 38 centers participated in the translational study, and samples for IL analyses were available in $23.8 \%$ of the patients 
Fig. 5 Kaplan-Meier curve showing overall survival of patients according to interleukin score

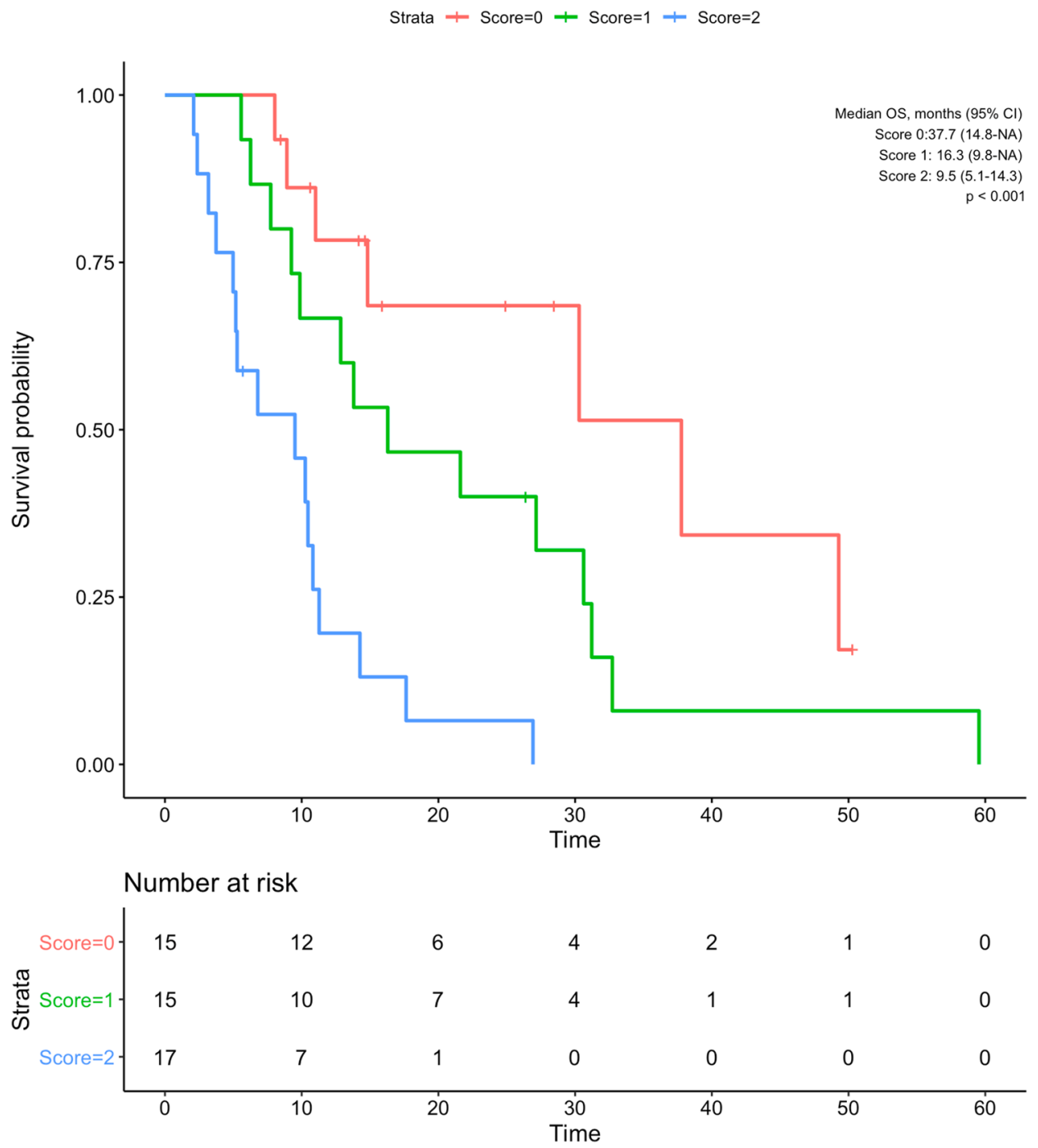

received sorafenib monotherapy. However, our study represents the single cohort proving the prognostic role of baseline IL-6 and IL- 8 values after sorafenib treatment of HCC in a Western cohort comprising high-quality data collected prospectively within a multicenter randomized trial. Nevertheless, further validation of these cut-off values in a larger cohort of patients receiving sorafenib treatment clearly is needed.

In conclusion, our study identified the prognostic value of baseline IL-6 and IL-8 values in advanced HCC patients receiving sorafenib treatment. The described cut-off values might be useful for individual patient allocation between different therapies in the era of checkpoint inhibitors or aggressive combination treatments. Additionally, baseline cytokine measurements should be included in future trials the assessing benefit of a new therapeutic regimen in advanced HCC. However, further validation of these cut-off values in larger cohorts is warranted.
Supplementary Information The online version contains supplementary material available at https://doi.org/10.1007/s00432-021-03627-1.

Author contributions OÖ, KS, PM, HJK, BS, JR, and MS: conception and design of the study; generation, collection, assembly, analysis and/or interpretation of data; drafting or revision of the manuscript; approval of the final version of the manuscript. JK, EM, GJ, ENT, NBK, TB, BB, JWV, CS, JB, AG, DP, RS, MW, and MP: generation, collection, assembly, analysis and/or interpretation of data; drafting or revision of the manuscript; approval of the final version of the manuscript.

Funding Open Access funding enabled and organized by Projekt DEAL. SORAMIC is an investigator-initiated trial sponsored by the University of Magdeburg. Financial support was granted by Sirtex Medical and Bayer Healthcare.

Availability of data and materials Data are available through corresponding author upon reasonable request. 


\section{Declarations}

Conflict of interest Maciej Pech: Grants: Sirtex, Bayer; Personal fees: Sirtex. Peter Malfertheiner: Grants: Bayer, Sirtex. Jens Ricke: Grants: Sirtex, Bayer; Personal fees: Sirtex, Bayer. Max Seidensticker: Personal fees: Bayer, Sirtex.

Ethic approval and patient consent The study protocol was approved by the competent authorities as well as the institutional review board, and all patients gave written informed consent.

Open Access This article is licensed under a Creative Commons Attribution 4.0 International License, which permits use, sharing, adaptation, distribution and reproduction in any medium or format, as long as you give appropriate credit to the original author(s) and the source, provide a link to the Creative Commons licence, and indicate if changes were made. The images or other third party material in this article are included in the article's Creative Commons licence, unless indicated otherwise in a credit line to the material. If material is not included in the article's Creative Commons licence and your intended use is not permitted by statutory regulation or exceeds the permitted use, you will need to obtain permission directly from the copyright holder. To view a copy of this licence, visit http://creativecommons.org/licenses/by/4.0/.

\section{References}

Abou-Alfa GK, Meyer T, Cheng AL, El-Khoueiry AB, Rimassa L, Ryoo BY, Cicin I, Merle P, Chen Y, Park JW, Blanc JF, Bolondi L, Klümpen HJ, Chan SL, Zagonel V, Pressiani T, Ryu MH, Venook AP, Hessel C, Borgman-Hagey AE, Schwab G, Kelley RK (2018) Cabozantinib in patients with advanced and progressing hepatocellular carcinoma. N Engl J Med 379(1):54-63

Bergmann J, Müller M, Baumann N, Reichert M, Heneweer C, Bolik J, Lücke K, Gruber S, Carambia A, Boretius S, Leuschner I, Becker T, Rabe B, Herkel J, Wunderlich FT, Mittrücker HW, Rose-John S, Schmidt-Arras D (2017) IL-6 trans-signaling is essential for the development of hepatocellular carcinoma in mice. Hepatology 65(1):89-103

Bruix J, Qin S, Merle P, Granito A, Huang YH, Bodoky G, Pracht M, Yokosuka O, Rosmorduc O, Breder V, Gerolami R, Masi G, Ross PJ, Song T, Bronowicki JP, Ollivier-Hourmand I, Kudo M, Cheng AL, Llovet JM, Finn RS, LeBerre MA, Baumhauer A, Meinhardt G, Han G (2017) Regorafenib for patients with hepatocellular carcinoma who progressed on sorafenib treatment (RESORCE): a randomised, double-blind, placebo-controlled, phase 3 trial. Lancet 389(10064):56-66

Carpizo DR, Gensure RH, Yu X, Gendel VM, Greene SJ, Moore DF, Jabbour SK, Nosher JL (2014) Pilot study of angiogenic response to yttrium-90 radioembolization with resin microspheres. J Vasc Interv Radiol 25(2):297-306.e291

Chan SL, Mo FK, Wong CS, Chan CM, Leung LK, Hui EP, Ma BB, Chan AT, Mok TS, Yeo W (2012) A study of circulating interleukin 10 in prognostication of unresectable hepatocellular carcinoma. Cancer 118(16):3984-3992

Chien MH, Yeh CB, Li YC, Wei LH, Chang JH, Peng YT, Yang SF, Kuo WH (2011) Relationship of interleukin-8 gene polymorphisms with hepatocellular carcinoma susceptibility and pathological development. J Surg Oncol 104(7):798-803

El-Serag HB (2012) Epidemiology of viral hepatitis and hepatocellular carcinoma. Gastroenterology 142(6):1264-1273.e1261
Finn RS, Qin S, Ikeda M, Galle PR, Ducreux M, Kim TY, Kudo M, Breder V, Merle P, Kaseb AO, Li D, Verret W, Xu DZ, Hernandez S, Liu J, Huang C, Mulla S, Wang Y, Lim HY, Zhu AX, Cheng AL (2020) Atezolizumab plus bevacizumab in unresectable hepatocellular carcinoma. N Engl J Med 382(20):1894-1905

Fousek K, Horn LA, Palena C (2020) Interleukin-8: a chemokine at the intersection of cancer plasticity, angiogenesis, and immune suppression. Pharmacol Ther 219:107692

Jang JW, Oh BS, Kwon JH, You CR, Chung KW, Kay CS, Jung HS (2012) Serum interleukin-6 and C-reactive protein as a prognostic indicator in hepatocellular carcinoma. Cytokine 60(3):686-693

Kahraman DC, Kahraman T, Cetin-Atalay R (2019) Targeting PI3K/ Akt/mTOR pathway identifies differential expression and functional role of IL8 in liver cancer stem cell enrichment. Mol Cancer Ther 18(11):2146-2157

Kakumu S, Shinagawa T, Ishikawa T, Yoshioka K, Wakita T, Ida N (1993) Interleukin 6 production by peripheral blood mononuclear cells in patients with chronic hepatitis B virus infection and primary biliary cirrhosis. Gastroenterol Jpn 28(1):18-24

Koch AE, Polverini PJ, Kunkel SL, Harlow LA, DiPietro LA, Elner VM, Elner SG, Strieter RM (1992) Interleukin-8 as a macrophagederived mediator of angiogenesis. Science 258(5089):1798-1801

Kudo M (2021) Impact of multi-drug sequential therapy on survival in patients with unresectable hepatocellular carcinoma. Liver Cancer 10(1):1-9

Kudo M, Finn RS, Qin S, Han KH, Ikeda K, Piscaglia F, Baron A, Park JW, Han G, Jassem J, Blanc JF, Vogel A, Komov D, Evans TRJ, Lopez C, Dutcus C, Guo M, Saito K, Kraljevic S, Tamai T, Ren M, Cheng AL (2018) Lenvatinib versus sorafenib in first-line treatment of patients with unresectable hepatocellular carcinoma: a randomised phase 3 non-inferiority trial. Lancet 391(10126): 1163-1173

Lai SC, Su YT, Chi CC, Kuo YC, Lee KF, Wu YC, Lan PC, Yang MH, Chang TS, Huang YH (2019) DNMT3b/OCT4 expression confers sorafenib resistance and poor prognosis of hepatocellular carcinoma through IL-6/STAT3 regulation. J Exp Clin Cancer Res 38(1):474

Li Y, Chen G, Han Z, Cheng H, Qiao L, Li Y (2020) IL-6/STAT3 signaling contributes to sorafenib resistance in hepatocellular carcinoma through targeting cancer stem cells. Onco Targets Ther 13:9721-9730

Llovet JM, Lencioni R (2020) mRECIST for HCC: performance and novel refinements. J Hepatol 72(2):288-306

Llovet JM, Peña CE, Lathia CD, Shan M, Meinhardt G, Bruix J (2012) Plasma biomarkers as predictors of outcome in patients with advanced hepatocellular carcinoma. Clin Cancer Res 18(8):2290-2300

Llovet JM, Ricci S, Mazzaferro V, Hilgard P, Gane E, Blanc JF, de Oliveira AC, Santoro A, Raoul JL, Forner A, Schwartz M, Porta C, Zeuzem S, Bolondi L, Greten TF, Galle PR, Seitz JF, Borbath I, Häussinger D, Giannaris T, Shan M, Moscovici M, Voliotis D, Bruix J (2008) Sorafenib in advanced hepatocellular carcinoma. N Engl J Med 359(4):378-390

Miyahara K, Nouso K, Tomoda T, Kobayashi S, Hagihara H, Kuwaki K, Toshimori J, Onishi H, Ikeda F, Miyake Y, Nakamura S, Shiraha H, Takaki A, Yamamoto K (2011) Predicting the treatment effect of sorafenib using serum angiogenesis markers in patients with hepatocellular carcinoma. J Gastroenterol Hepatol 26(11):1604-1611

Naugler WE, Sakurai T, Kim S, Maeda S, Kim K, Elsharkawy AM, Karin M (2007) Gender disparity in liver cancer due to sex differences in MyD88-dependent IL-6 production. Science 317(5834):121-124 
Niu LL, Cheng CL, Li MY, Yang SL, Hu BG, Chong CCN, Chan SL, Ren J, Chen GG, Lai PBS (2018) ID1-induced p16/IL6 axis activation contributes to the resistant of hepatocellular carcinoma cells to sorafenib. Cell Death Dis 9(9):852

Porta C, De Amici M, Quaglini S, Paglino C, Tagliani F, Boncimino A, Moratti R, Corazza GR (2008) Circulating interleukin-6 as a tumor marker for hepatocellular carcinoma. Ann Oncol 19(2):353-358

Ricke J, Klümpen HJ, Amthauer H, Bargellini I, Bartenstein P, de Toni EN, Gasbarrini A, Pech M, Peck-Radosavljevic M, Popovič P, Rosmorduc O, Schott E, Seidensticker M, Verslype C, Sangro B, Malfertheiner P (2019) Impact of combined selective internal radiation therapy and sorafenib on survival in advanced hepatocellular carcinoma. J Hepatol 71(6):1164-1174

Sanmamed MF, Carranza-Rua O, Alfaro C, Oñate C, Martín-Algarra S, Perez G, Landazuri SF, Gonzalez A, Gross S, Rodriguez I, Muñoz-Calleja C, Rodríguez-Ruiz M, Sangro B, López-Picazo JM, Rizzo M, Mazzolini G, Pascual JI, Andueza MP, Perez-Gracia JL, Melero I (2014) Serum interleukin-8 reflects tumor burden and treatment response across malignancies of multiple tissue origins. Clin Cancer Res 20(22):5697-5707

Schmidt-Arras D, Rose-John S (2016) IL-6 pathway in the liver: from physiopathology to therapy. J Hepatol 64(6):1403-1415

Seidensticker M, Powerski M, Seidensticker R, Damm R, Mohnike K, Garlipp B, Klopffleisch M, Amthauer H, Ricke J, Pech M (2017) Cytokines and (90)Y-radioembolization: relation to liver function and overall survival. Cardiovasc Intervent Radiol 40(8):1185-1195
Shao YY, Lin H, Li YS, Lee YH, Chen HM, Cheng AL, Hsu CH (2017) High plasma interleukin-6 levels associated with poor prognosis of patients with advanced hepatocellular carcinoma. Jpn J Clin Oncol 47(10):949-953

Sun F, Wang J, Sun Q, Li F, Gao H, Xu L, Zhang J, Sun X, Tian Y, Zhao Q, Shen H, Zhang K, Liu J (2019) Interleukin-8 promotes integrin $\beta 3$ upregulation and cell invasion through PI3K/Akt pathway in hepatocellular carcinoma. J Exp Clin Cancer Res 38(1):449

Wang CQ, Sun HT, Gao XM, Ren N, Sheng YY, Wang Z, Zheng Y, Wei JW, Zhang KL, Yu XX, Zhu Y, Luo Q, Yang LY, Dong QZ, Qin LX (2016) Interleukin-6 enhances cancer stemness and promotes metastasis of hepatocellular carcinoma via up-regulating osteopontin expression. Am J Cancer Res 6(9):1873-1889

Wang W, Wang J, Zhang X, Wang Y, Shi J, Jia X, Dang S (2021) Atezolizumab plus bevacizumab for unresectable or metastatic hepatocellular carcinoma: a cost-effectiveness analysis. J Clin Oncol 39(3):295

Wong VW, Yu J, Cheng AS, Wong GL, Chan HY, Chu ES, Ng EK, Chan FK, Sung JJ, Chan HL (2009) High serum interleukin-6 level predicts future hepatocellular carcinoma development in patients with chronic hepatitis B. Int J Cancer 124(12):2766-2770

Publisher's Note Springer Nature remains neutral with regard to jurisdictional claims in published maps and institutional affiliations.

\section{Authors and Affiliations}

\section{Osman Öcal ${ }^{1}$ (1) - Kerstin Schütte ${ }^{2} \cdot J^{\prime}$ uozas Kupčinskas ${ }^{3} \cdot$ Egidijus Morkunas $^{3}$ - Gabija Jurkeviciute ${ }^{3}$. Enrico N. de Toni ${ }^{4} \cdot$ Najib Ben Khaled $^{4}$. Thomas Berg ${ }^{5} \cdot$ Peter Malfertheiner ${ }^{4} \cdot$ Heinz Josef Klümpen $^{6}$. Christian Sengel $^{7}$. Bristi Basu ${ }^{8}$. Juan W. Valle ${ }^{9}$. Julia Benckert ${ }^{10} \cdot$ Antonio Gasbarrini $^{11}$ - Daniel Palmer ${ }^{12}$. Ricarda Seidensticker ${ }^{1} \cdot$ Moritz Wildgruber $^{1} \cdot$ Bruno Sangro $^{13} \cdot$ Maciej Pech $^{14} \cdot$ Jens Ricke $^{1} \cdot$ Max Seidensticker $^{1}$ (D)}

1 Department of Radiology, University Hospital, Ludwig Maximilian University of Munich, Marchioninistrasse 15, 81377 Munich, Germany

2 Department of Internal Medicine and Gastroenterology, Niels-Stensen-Kliniken Marienhospital, Osnabrück, Germany

3 Institute for Digestive Research and Department of Gastroenterology, Medical Academy, Lithuanian University of Health Sciences, Kaunas, Lithuania

4 Department of Medicine II, University Hospital, LMU Munich, Munich, Germany

5 Klinik Und Poliklinik Für Gastroenterologie, Sektion Hepatologie, Universitätsklinikum Leipzig, Leipzig, Germany

6 Department of Medical Oncology, Amsterdam University Medical Centers, University of Amsterdam, Amsterdam, The Netherlands

7 Radiology Department, Grenoble University Hospital, La Tronche, France
8 Department of Oncology, University of Cambridge, Cambridge, UK

9 Division of Cancer Sciences and Department of Medical Oncology, The Christie NHS Foundation Trust, University of Manchester, Manchester, UK

10 Department of Hepatology and Gastroenterology, Charité-Universitätsmedizin Berlin, Campus Virchow Klinikum, Berlin, Germany

11 Fondazione Policlinico Universitario Gemelli IRCCS, Universita' Cattolica del Sacro Cuore, Roma, Italy

12 Molecular and Clinical Cancer Medicine, University Hospitals and Clatterbridge, University of Liverpool, Liverpool, UK

13 Liver Unit, Clínica Universidad de Navarra, Pamplona, Spain

14 Departments of Radiology and Nuclear Medicine, University of Magdeburg, Magdeburg, Germany 